\title{
Advancing low-carbon emissions in Asia: mitigation of greenhouse gases and enhancing economic feasibility for major sectors
}

\author{
Chew Tin Lee ${ }^{1}$ Nor Erniza Mohammad Rozali ${ }^{2}$ Jiří Jaromír Klemeš ${ }^{3} \cdot$ Sirintornthep Towprayoon $^{4}$
}

Published online: 3 March 2018

๑) Springer-Verlag GmbH Germany, part of Springer Nature 2018

Asia is the factory of the world for many manufacturing activities, for which promoting sustainable growth while maintaining a low-carbon or $\mathrm{CO}_{2}$ emission profile is crucial. Decoupling emission of high greenhouse gases without compromising the economic growth is a great challenge. Advancement in clean technology and environmental policies, targeting the key emitter of GHG emissions, is crucial to drive the low $\mathrm{CO}_{2}$ emissions development. Implementation of these measures would require continuous consensus building and the concerted efforts, involving multiple stakeholders at local and international levels, to reduce the carbon footprints.

The progress on low $\mathrm{CO}_{2}$ emissions development has not been fast enough due to the gaps among the stakeholders including the central and local governments, experts and business entities and the community at large. International conferences could serve as the platform to bridge these gaps. The conference series of International Conference on Low Carbon Asia 2016 (ICLCA'16), November 23-25, 2016, aimed to accelerate the transformation of Asia toward sustainable development with low $\mathrm{CO}_{2}$ emissions. The past ICLCA conference series <www.utm.my/iclca $>$ was held

Chew Tin Lee

ctlee@utm.my

1 Faculty of Chemical and Energy Engineering, Universiti Teknologi Malaysia (UTM), 81310 Johor Bahru, Johor, Malaysia

2 Department of Chemical Engineering, Faculty of Engineering, Universiti Teknologi PETRONAS, 32610, Seri Iskandar, Perak Darul Ridzuan, Malaysia

3 Sustainable Process Integration Laboratory - SPIL, NETME Centre, Faculty of Mechanical Engineering, Brno University of Technology, - VUT Brno, Technická 2896/2, 61600 Brno, Czech Republic

4 The Joint Graduate School of Energy and Environment, King Mongkut's University of Technology Thonburi, 126 Prachauthit Rd, Bangmod, Tungkru, Bangkok 10140, Thailand in Johor Bahru and Kuala Lumpur, Malaysia, in the year 2015 and 2016 (ICLCA'15 and ICLCA'16), followed by in Bangkok, Thailand (ICLCA'17). Two series of the Annual Meeting of Low Carbon Asia Research Network (LoCARNet) have joined the ICLCA in 2015 and 2017. The LoCARNet $<$ lcs-rnet.org/about_locarnet $>$ is a network for multilayered stakeholders to promote research cooperation related to low-carbon growth and policy making. The key members of LoCARNet are from the ASEAN + 3 countries (Japan, China and Republic of Korea) as led by the Secretariat based in the Institute for Global Environmental Strategies (IGES), Japan.

ICLCA'16 has attracted 150 international researchers, local authorities and policymakers from the public and private institutions of over 15 countries (China, Czech Republic, Denmark, Greece, India, Indonesia, Japan, Republic of Korea, Lithuania, Kazakhstan, Malaysia, the Philippines, Taiwan, Thailand and Vietnam). The event was graced by the Deputy Minister, Ministry of Energy, Green Technology and Water (KeTTHA), Malaysia, with exhibition booths supported by the Malaysian local authorities from Kuala Lumpur City Hall, Johor Bahru Tengah and Kulai Municipal Councils.

Up to 15 thematic topics had been announced for the conference, indicating its multidisciplinary and holistic approach toward finding solutions for a more sustainable future. The topics included:

- Urban planning

- Green building and architecture

- Smart and sustainable energy systems

- Sustainable solid waste management

- Sustainable production and consumption

- Low-carbon transportations system

- Green policies

- Environmental impact assessment

- Creative ICT

- Behavior change and education ecosystem 
- Land use, land-use change and forestry (LULUCF)

- Optimization, modeling and simulation for sustainable development

- Green tourism

- Public participation and consensus building

- Carbon Capture and Storage (CCS)

The conference series will continue; the 4th ICLCA 2018 will be held in Johor Bahru, Malaysia from October 24 to October 26, $2018<w w w . u t m . m y / i c l c a>$.

The 9th Regional Conference on Chemical Engineering (RCChE'16), Postgraduate Symposium on Chemical and Energy Engineering (POISChE) and ASEAN Partnership in Research on Energy Sustainability (ASPIRE) underscoring ASEAN commitment, was held on November 21-22, 2016 in Kuala Lumpur, Malaysia. RCChE'16 has attracted up to 310 international delegates.

$\mathrm{RCChE}$ is an annual program to share the most updated technology and research of common regional issues as well as to publicize the research work of AUN/SEED-Net members. These conference series have given opportunities for participants to discuss future collaborations and activities related to chemical engineering fields relevant to sustainability.

RCChE' 16 focused on the latest developments in:

- Process Systems Engineering (PSE)

- Process Control and Safety (PCS)

- Chemical Reaction Engineering (CRE)

- Separation Technology (SEP)

- Chemical Engineering Education (CEE)
- Biofuels and Energy (ENG)

- Organic Chemistry and Natural Products (NAT)

- Ceramic, Advanced Materials and Nanotechnology (MAT)

- Polymer Materials and Processing (PLM)

- Environmental Engineering (ENV)

- Food and Biotechnology (BIO)

- Oil, Gas and Petroleum (OGP)

A Scientific Committee consisting of 50 world-leading personalities reviewed the 372 papers submitted for the oral and poster presentation for both conferences (ICLCA' 16 and RCChE' 16). Following the further selection procedures, 35 invitations have been sent to the authors to prepare articles, and 11 papers have been finally accepted to this special section of this issue of Clean Technologies and Environmental Policy entitled "Advancing Low-Carbon Emissions in Asia and beyond".

This special section of this issue of Clean Technologies and Environmental Policy has been published within a brief period, which would not have been possible without the valuable help from 32 reviewers who contributed their valuable time and expertise to support the submission of high-quality manuscripts to this special section. The Guest Editors would like to thank all of them and especially those engaged in multiple reviewing and also involved in the ICLCA'16 and RCChE'16 Scientific Committee.

The CTEP journal publisher and the Editor in Chief with the Regional Editors deserve the thanks for their support and encouragement. 